\title{
$\mathrm{PH} 101_{\text {debate }}$
}

a debate Hacia una nueva institucionalidad cultural. Modelos emergentes de gestión...

| coordina Jesús Carrillo Castillo

\section{Modelos emergentes, modelos utópicos. Siempre necesarios e innovadores}

Óscar Navajas Corral | Dpto. de Historia y Filosofía, Universidad de Alcalá

URL de la contribución <www.iaph.es/revistaph/index.php/revistaph/article/view/4727>

La palabra cultura impregna nuestra visión del mundo (DÍAZ DE RADA, 2012: 28). Se sustenta en la idea de socialización y se construye, por tanto, en la interrelación de las relaciones humanas. La cultura es lo que permite que socialicemos y que nos vinculemos de alguna forma; lo que implica, por un lado, comunicación y, por otro, que no pertenezca a ningún individuo en concreto. Se crea y cobra vida en el espacio público por medio de la comunicación y del aprendizaje social (DÍAZ DE RADA, 2012: 47). Esta concepción de cultura nos desmarca del sentido actual de cultura como propiedad, producto y mercancía; pero, sin embargo, nos permite entender que todo ser humano sea agente y gestor de la cultura.

La cultura, tal y como es usada socialmente y por las dinámicas instituyentes de gobiernos, administraciones e instituciones, es una sucesión de muros levantados para legitimar una diversidad de imaginarios clasificados, subjetivos y ficticios en los que se abren puertas, cuyo acceso está condicionado a aceptar cada uno de esos imaginarios excluyentes (DÍAZ DE RADA, 2012: 205). Esta forma de entender la cultura encasilla, limita y excluye el verdadero sentido global, holístico y horizontal de la acción cultural.

Al formular estas sentencias estamos afirmando que el modelo actual de gestionar la cultura tiene el peligro de congelarla en el tiempo, convirtiéndola en algo artificioso, únicamente vivo en el imaginario de una única memoria colectiva y no en la acción social. Sin embargo, también estamos estableciendo que una nueva institucionalidad de la cultura debería acercarse a los planteamientos del procomún, puesto que, como hemos comentado al principio, no entendemos la cultura como una propiedad, sino como un proceso de relaciones; y a la institución cultural (el museo) como la encargada de gestionar esa práctica de interrelaciones. En esta suma de relaciones de individuos y acciones es donde podría estar la diferencia del modelo de institucionalidad.

La pregunta en este momento es: ¿cómo se gestionan relaciones? A priori parece complejo que los museos puedan cambiar sus objetivos enfocados en las manifestaciones culturales (tangibles e intangibles) y gestionar relaciones. Sin embargo, no han sido pocos los momentos de la intensa historia de los museos y de la corta trayectoria de la museología en los que esto ya se ha producido. Únicamente apuntar cómo en la década de los setenta y ochenta del s. XX el movimiento de la Nueva Museología ya invirtió la visión orientada en las musas, para dirigirla a su progenitora, Mnemosine, la memoria, poniendo el acento del trabajo museológico en los sujetos, las comunidades, más que en los objetos.

No debemos dejar de tener presente que los museos son espacios desnaturalizados, ucrónicos, que se encuentran embaucados por un sistema de símbolos y que se balancean entre lo universal y la identidad local. Son un cajón de sastre del pasado, almacenes de utopías -o de complejos- de la sociedad. Estos complejos son, entre otros, entender los museos como elementos para el desarrollo turístico y económico, como si pudiesen ser "la gallina de los huevos de oro"; establecerlos como espejos de la memoria de la sociedad, como si toda la cultura de una comunidad pudiera estar en ellos y toda la comunidad se sintiera pertinente de una misma cultura; o la utopía de la cohesión social, como si las sociedades o comunidades fuesen bloques compactos, pasivos y unitarios. Lo interesante de los museos, en realidad, es que son la construcción de la mirada con el Otro, y esta mirada, necesita de la confrontación y la disputa positiva. 


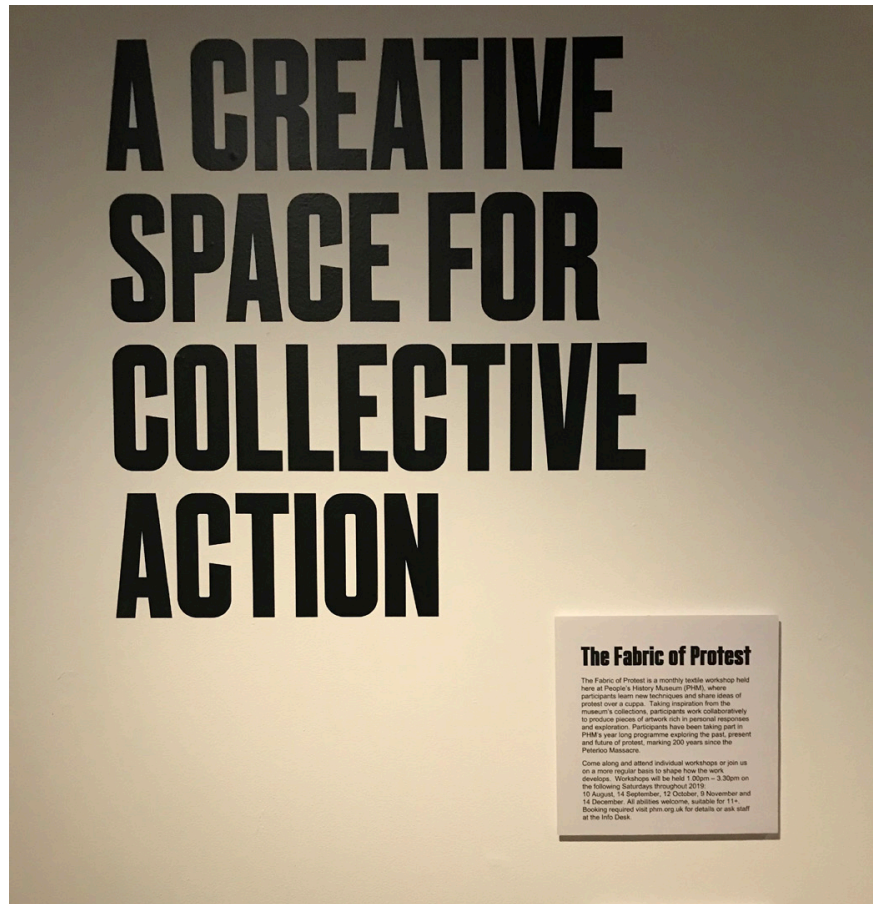

Cartel acción colectiva People Museum Manchester | foto Óscar Navajas Corral

Lamentablemente, el modelo de instituciones culturales que ha "vencido" en nuestra sociedad es aquel donde el producto aglutina la capacidad de visibilización social. Los museos continúan siendo productores en los que se mezclan el simulacro, el espectáculo y los conflictos de "poder", bajo la mirada benévola de ser centros para la cultura ciudadana. Este modelo es el que se deriva de la lógica del mercado, al que las políticas públicas se han sumado ante la caducidad del modelo de democratización cultural y la incapacidad de llevar a cabo políticas de democracia cultural. La gestión de la cultura se fundamenta en generar productos que se amolden a las inquietudes sociales. Inquietudes que, a su vez, son generadas por estándares impuesto por un reducido número de grupos de poder, lejanos a la idea de una cultura plural, diversa e interconectada.

¿Existe alternativa? Como apunta Javier Rodrigo Montero: "(...) tendría que ver con comenzar a experimentar un nuevo marco público-comunitario que supere el denostado marco público-privado que tanto ha mar- cado las políticas culturales". Es aquí donde entra una visión de acción social de la cultura y, si se quiere, del procomún. Esto se asocia a los espacios en donde se está forjando esta alternativa y que Sergio Ramos Cebrián, acertadamente, denominaba como "esos otros lugares que son focos de transferencia cultural excéntrica y bárbara (...) donde se despliegan nuevas formas de innovación y alternativa social (...) y (...), se materializan los nuevos gradientes de los derechos culturales, en sentido democrático".

En este sentido, desde hace décadas se han vuelto a potenciar las experiencias y modelos de participación e innovación desde lo social. Estos modelos emergentes se pueden localizar en la actualización de la Nueva Museología por medio de la Sociomuseología, la Museología Social (NAVAJAS CORRAL, 2020) o la Museología Crítica; la reactivación de los Parish Map; la cartografía de la memoria; la animación socia-cultural; el movimiento investigación-acción participación (IAP); o el procomún. Los ejemplos de aplicación son múltiples y diversos: Espacio Vecinal Arganzuela (EVA), el Cubo Verde, Proyecto Fraguas, Rey Heredia, Tabacalera Madrid, el Ecomuseo del Río Caicena, el Ecomuseo de les Valls d'Àneu, La Ponte-Ecomuséu, los procesos BIComún, el proyecto El Raval 6000 años de historia, o Zerain Paisaje Cultural, entre otros.

Todos ellos comparten el planteamiento donde la dinámica de participación es algo consustancial en los grupos sociales y que la focalización del trabajo es la de limitar el imaginario que se ha impuesto en la sociedad que hace de nuestras propias relaciones sociales (de la cultura) un objeto de consumo.

\section{BIBLIOGRAFÍA}

- DÍAZ DE RADA, Á. (2012) Cultura, antropología y otras tonterías. Madrid: Editorial Trotta, 2012

- NAVAJAS CORRAL, Ó. (2020) Nueva museología y museología social. Una historia narrada desde la experiencia española. Gijón: Trea, 2020 